


\title{
Early childcare, child cognitive outcomes and inequalities in the UK
}

\author{
Daniela Del Boca*, Daniela Piazzalunga**, Chiara Pronzato***
}

\begin{abstract}
In this empirical analysis, we estimate the link between formal childcare and child cognitive outcomes, controlling for a large number of variables. We use the Millennium Cohort Survey (MCS) for the United Kingdom, which provides very detailed information about several modalities of childcare as well as several child outcomes. We also simulate how an increase in formal childcare attendance can affect inequalities across children. Our results indicate that childcare attendance has a positive impact on child cognitive outcomes, which are stronger for children from low socioeconomic background.
\end{abstract}

JEL: J13, D1, I21

Keywords: Childcare, Child cognitive outcomes

*University of Turin and CHILD Collegio Carlo Alberto

** IRVAPP Trento and CHILD Collegio Carlo Alberto

***University of Turin and CHILD Collegio Carlo Alberto

The paper will be published as "Child care arrangements and social Inequalities in the UK" (with D. Piazzalunga and C. Pronzato) in Early Child Care and inequalities: an international perspective (editor H. Blossfeld et al) Elgar 2017 


\section{Introduction}

Early childcare plays an important role in the production of cognitive skills. What determines cognitive ability and behavioural development early in life is of crucial policy importance. Returns on investments in early childhood are higher than those on investments at later stages. Early investments have also longer term impact: they play a very significant role in cognitive, social and behavioural outcomes in adult age (Carneiro and Heckman 2003).

While early psychological theories have stressed the need for maternal care, more recent studies in sociology and economics have shown that other childcare arrangements do not necessarily produce negative outcomes. In particular it has been shown that formal care may foster the development of the child to the same extent as maternal care.

Significant differences emerge for children of different backgrounds. Formal childcare is more beneficial to disadvantaged children, compensating the possible detrimental effect of living in disadvantaged circumstances. Thus it may play also a significant role in reducing disparities. In addition, subsidised childcare helps low-income mothers not to experience hour-related problem at work (Press et al. 2006).

The objective of this research is to explore the impact of early childcare on child cognitive outcomes. We utilize the Millennium Cohort Survey (MCS) for the United Kingdom, which provides very detailed information about several modalities of childcare as well as several child outcomes.

In our empirical analysis, we estimate the association between formal childcare and child cognitive outcomes, allowing the effect of formal childcare to be different for children from different family backgrounds, controlling for a large number of variables (regarding the child, the mother, the father, the household). In a second step, we simulate how an increase in formal childcare attendance can affect inequalities across children. Our results show that childcare attendance has a positive impact on child cognitive outcomes, which are stronger for children from low socio-economic background.

\section{Previous studies}

While a large number of studies have analysed the impact of formal childcare in the short and long run, only a few have explored the impact on children disparities. Recent studies focusing on the impact of childcare on child outcomes have reported strong heterogeneity by social status. The largest number of studies concern the US, where childcare is mostly private and unevenly regulated. Most of these studies report a negative effect on outcomes for children who attended childcare before kindergarten (Brooks-Gunn, Han and Waldfogel 2002). However, the results vary significantly across 
families, children, and childcare type. Using the National Longitudinal Survey of Youth 1979, a study reports that formal care has significant effects on cognitive achievement of children of low educated mothers (Bernal 2008). Fitzpatrick (2008) finds that children with low educated parents benefit most from childcare attendance.

In European countries, where formal childcare is mainly public, most analyses find a consistent positive impact in areas where public childcare is more widely available and of higher quality. Because access to these programs is not limited to disadvantaged children, the results found for universal programs can be informative about the effects of modes of care on children across a wide range of socio-economic backgrounds. The positive results of formal childcare on child outcomes are stronger and more consistent in Northern European countries. A recent analysis of the impact of a large increase in childcare supply in Norway in the 1970s shows strong and positive impacts on long term children's outcomes (such as years of education and college attendance, and earnings outcomes) especially for children of low-educated parents (Havnes and Mogstad 2011). A study in Germany reports that formal childcare attendance has a positive impact on children's cognitive and noncognitive abilities of children of less educated families (Felfe and Lalive 2014). Finally, Datta Gupta and Simonsen (2010) compare different types of formal childcare on non-cognitive outcomes and find strong positive effects only for children of low educated mothers.

\section{Formal child care in the UK}

In the UK (as in the rest of Europe) the availability of formal and accessible childcare for the very young (0-2) is very low. Compared to other European countries, the UK introduced free childcare for 3 and 4 years old only recently (all children aged 5 attend primary school), with the National Childcare Strategy of 1998. By 2000, in England all 4 year olds have been entitled to receive free part-time early education and by 2005 all 3 years olds. Similar policies are in place in Scotland and Wales (Blanden et al. 2014). At the beginning the entitlement was 12.5 hours per week, for 33 weeks per year; by 2010 it increased to 15 hours per week, 38 weeks a year. In 2010, take-up of the entitlement was 97\% among 4 years old, and 87\% among 3 years old. While the policy did not increase the public provision of formal care places, most early education for 3 and 4 years old is delivered by nursery school and primary schools (Gibb et al 2011). In addition, already before 2000 most children were enrolled in some form of childcare, and the main change has been the entitlement to free formal care (Blanden et al. 2014).

Childcare for children under 3 is mainly provided by the private market, and children receiving early education mainly came from high socio-economic families. From 2013, the legal entitlement to 15 hours of free early education has been extended to every disadvantaged 2 year olds (covering about $40 \%$ of 2 years old). However, the expansion in provision is expected mainly from the private 
childcare market, and the quality is on average lower than in formal care for 3 and 4 years olds (Gibb et al 2011). Thus, strong differences persist across childcare types, their quality and use. For an extensive description of the characteristics of the UK childcare and its evolution overtime see West (2006).

Children in our sample are born in 1999/2000, thus they are concerned by the free early childcare for 4 years old, and some of them by the provision for 3 years old, but none of them was involved in the policy for 2 years old, which has been put in place when they were already older.

\section{Data}

\subsection{The Millennium Cohort Study}

The Millennium Cohort Study (MCS) is a longitudinal survey conducted by the Centre for Longitudinal Studies (CLS) that tracks the lives of a sample of about 19,000 babies born in the UK in the year 2000/2001. The survey is conducted in several waves, with the first one concentrating on the circumstances of the pregnancy and birth as well as the first few months of life. The first part of the survey also contains important information about the socio-economic background of the family into which the child is born. The second wave took place when the children were about 3 years old, and the main focus was on continuity and change in the family as well as the parenting environment to extract information about the child's development. In the third wave in 2006, the children were at the age to start primary school. The fourth wave took place in 2008, and the fifth in 2012. For our analysis we use wave 1 through 4 .

\subsection{The sample}

In wave 1, the survey consists of 18,552 children. We exclude 256 twins, since childcare arrangements and their effects may be different when more children have to be looked after, and 40 children whose main caregiver (who therefore answered the questions concerning the child) is not the mother. In addition, we lose around $10 \%$ of the sample between the second and the third wave, and another $10 \%$ between the third and the fourth survey

Our main independent variable is formal childcare attendance when the child is 18 months. It is constructed using information in wave 2 (when the child is 3 years old); however, a non-negligible number of mothers (around 2,000) did not answer these questions, and are excluded from the sample (probably because of a filter error in the questionnaire). Finally, we have also dropped children whose outcomes all resulted as missing. Our final sample consists of 10,001 observations.

\section{Methodology}

The empirical analysis follows two steps. In the first step, we analyze the association between early formal childcare and child cognitive outcomes, allowing the effect to be different for children from 
different family backgrounds. We control for a large number of control variables (regarding the child, the mother, the father, the household). In the second step, we simulate how an increase in formal childcare attendance can affect inequalities across children.

\subsection{The different effect of formal care by mothers' education}

First, we estimate the following equation:

$$
Y_{i a}=\beta_{0}+K_{i 9} \beta_{1}+F_{i 18} \beta_{2}+A_{i} \beta_{3}+F_{i 18} * A_{i} \beta_{4}+X_{i 9} \beta_{5}+Z_{i a} \beta_{6}+\varepsilon_{i a}
$$

where $Y_{i a}$ refers to a vector of cognitive outcomes of the child $i$ when she is $a$ years old $(a=3,5,7), K_{i 9}$ is a vector of early child endowment (motion, motor and communication development) of the child when she is 9 months old, $F_{i 18}$ is a dummy variable taking value 1 if the main childcare modality of the child at 18 months is formal care, $A_{i}$ is the age at which the mother left education, $X_{i 9}$ is a vector of time-invariant characteristics of the child $i$ and her family measured when she is 9 months old, $Z_{i a}$ is a vector of time-variant characteristics of the child $i$ and her family measured when she is $a$ years old, and $\varepsilon_{i a}$ is the stochastic error. $\beta_{0}, \beta_{1}, \ldots \beta_{6}$ are the parameters to be estimated with OLS. We study the effect of early childcare on eight cognitive outcomes $\left(Y_{i a}\right)$, two measured at age 3, three measured at 5 and three measured at age 7: Bracken School Readiness assessment (age 3 of the child), on Naming Vocabulary (age 3 and 5), Picture Similarity (age 5), Pattern Construction (age 5 and 7), Word Reading Score and the Number Skills (age 7). The child outcomes are detailed in the next section.

The coefficients of interest are $\beta_{2}$, the effect of formal care on child cognitive outcome, ceteris paribus, and $\beta_{4}$, the different effect of formal care by the age at which the mother left education (a continuous variable which depends on the level of education of the mother).

We control for a large number of variables, measured when the child is 9 months old $\left(X_{i 9}\right)$. We consider the child's characteristics (being immigrant, being a girl, birthweight, whether s/he was breastfed for at least 1 month, accidents at home, having been in a hospital); household's characteristics (other siblings, weekly equivalent income, if parents meet friends at least once a week, region of residence); mother's characteristics (age, hours of work per week, whether she held a job while pregnant, monthly wage, not employed, whether she experienced post-partum depression, a factor summarizing her feelings of tiredness and concern, a factor summarizing her feelings of irritability, whether she had lived with a single mother during childhood, whether she has a chronic illness, cigarettes smoked per day, whether she drinks at least once a week); father's characteristics (whether he is present, hours of work per week, monthly wage, a factor summarizing his feelings of tiredness and concern, a factor summarizing his feelings of irritability, whether he had lived with a single mother during childhood, cigarettes smoked per day, whether he drinks at least once a week). 
In order not to lose too many observations, we replace missing observation of the control variables with 0 and construct four missing variable indicators (for the child, the household, the mother, the father).

In addition, we control for the following variables, which may vary over time $\left(Z_{i a}\right)$ : the presence of the father at home, the presence of a new partner of the mother at home, household income, and the arrival of new siblings.

\subsection{Formal care may reduce inequality}

Next, we focus on the reduction of disparities if more children would attend formal care. We utilize the coefficient of variation, a measure of dispersion, and the percentage of children with low scores in cognitive tests (with a test below or equal to the results of the first quartile of the original distribution). The coefficient of variation (cv) is defined as the ratio between the standard deviation and the mean, and it is an appropriate statistics because it is independent from measurement unit.

We first compute the coefficient of variation and the percentage of children with low scores in the current/observed situation. Then, we progressively increase the number of children in formal care, allowing all children in the first, second, ..., tenth decile of the income distribution to attend formal care, and increasing their cognitive outcomes accordingly, exploiting the different return to attend formal care by level of income, while controlling for all the other independent variables. In these simulations, we use the level of income rather than the education of the mother since it is most admissible from a policy point view to justify a policy that makes poorer children attend formal childcare for free than children of lower educated parents. However, results are qualitatively the same in the two cases: children of lower educated mothers and/or children of poorer parents are the ones who get most by experiencing early formal childcare. In fact, as can be seen from Table 1, the level of education of the mother correlates with the level of income of the family: the higher the level of education, the higher the household's income. The average equivalent income per week is almost $583 £$ when the mother has the highest academic degree, $302 £$ if she has obtained a GCSE with grades A-C (the most common academic level), and only $175 £$ for the lowest educated. As other research has shown, parents with higher education are not only more able to provide higher quality time inputs to their children (Del Boca et al 2014) but they are also able to pay for (higher quality) formal care. On the contrary, low educated parents may be unable to afford to pay for having their children enrolled in formal care (even more beneficial for their children).

\section{TABLE 1 ABOUT HERE}

\subsection{The dependent variables: child cognitive outcomes}


In the Millennium Cohort Study, child outcomes are measured in three ways. A first group of outcomes is measured by the interviewer through a standardized test and focuses on the child's ability to perform certain tasks; a second group is reported by the teacher (when the child is 5 and 7) and concerns abilities and behaviour at school; a third group is reported by the mother and regards the child's behaviour at home.

We only consider the first group of outcomes, since it is more objective: mother's reports may lead to very biased results (for example, mothers may feel guilty about not staying at home and therefore be more lenient judges of the child's behaviour), while teacher-performed evaluations may be influenced by the other children in the class, which we are not able to take into account.

The Bracken School Readiness assessment is used to assess the basic concept development in young children. BBCS-R measures the comprehension of 308 functionally relevant educational concepts in 11 subtests or concept categories. Only 6 subsets have been implemented in the MCS: colours (primary and basic), letters (knowledge of upper- or lower- case letters), numbers/counting (single and double-digits numbers and assigning a number to a set of objects), sizes (concepts that describe one, two and three dimensions), comparisons (the ability to match or differentiate objects), and shapes (including lines, circles, squares, cubes, and pyramids). The Naming Vocabulary Verbal test assesses the spoken vocabulary of the child. Children are shown individual test items from booklets of colourful pictures of objects and asked to name the objects. The scale measures language ability, but picture recognition is also crucial. Low scores may also reflect reluctance to speak. For the Picture Similarity test, children are shown a row of 4 pictures on a page and asked to place a card with a fifth picture under the picture most similar to it. This assessment measures children's problem solving abilities.

The Pattern construction test assesses the child's accuracy and speed in constructing a design by putting together flat squares or solid cubes with black and yellow patterns on each side. In the Word reading test the child reads a series of words presented on a card out loud, thus giving an indication of his or her reading skills. The Number skills test is adapted from the NFER Progress in math test. In this assessment, children complete various tasks, covering the topics of numbers, shape, space and measures, and data handling.

The summary statistics of the child cognitive outcomes are summarized at Table 2 .

\section{TABLE 2 ABOUT HERE}

\section{Results}

Our results show that early childcare attendance is positively correlated with all child cognitive outcomes. The effect is statistically significant for School Readiness at age 3 (Table 3), Naming Vocabulary at age 5 (Table 4) and Number Skills at age 7 (Table 5). Considering the age of the 
mother when leaving education equal to 0 , attending formal care increases the child's score in School Readiness by about 7.7 points (mean: 105), in Naming Vocabulary by about 4 points (mean: 55) and in Number Skills by about 1.4 points (mean: 10). The effect may seem exceptionally large, but one should keep in mind that the interaction between formal care and education of the mother should be accounted for in order to have a realistic idea of the final effect.

The age at which the child's mother left school has a positive and significant impact on all the outcomes: more educated parents positively affect the cognitive outcomes of their children. The impact is larger on all cognitive outcomes for disadvantaged children,: indeed, the interaction between formal care and the age at which the mother left school is negative (significant for School Readiness at age 3, Naming Vocabulary at age 3 and 5 and Number Skills at age 7). Each additional year of education reduces the effect of formal care by 0.07 (Number Skills) - 0.36 (School Readiness) points.

\section{TABLE 3 ABOUT HERE}

TABLE 4 ABOUT HERE

TABLE 5 ABOUT HERE

Thus, we investigate what may happen to the cognitive outcomes of children in the presence of a policy which introduces (free) formal care for children in the first, second, ..., tenth decile of household's income. Note that according to our data, 13\% of children between age 1 and 2 attend formal childcare. When we allow for children of each decile to attend formal care, we increase that measure by about $9 \%$ each time, increasing the attendance rate to $22.7 \%$ until $100 \%$, when the children from every family background are in formal care.

The results are presented in Figure 1 to Figure 8 (one for each cognitive outcome), and show the reduction in disparities if children from low income families would attend formal care. The red point/bar represents the baseline condition, i.e. with the level of attendance, the coefficient of variation and the percentage of children with an outcome below or equal to the first quartile as it is before the simulation.

For School Readiness the coefficient of variation decreases from 0.153 until 0.148 , when all children in families with an income below or equal to the sixth decile are in formal care, and then it increases again. Afterwards the equalizing effect of formal care declines and the coefficient of variation increases again (i.e. the dispersion of results). However the percentage of children with a low score decreases constantly, from 23.5\% until 19.3\%. A similar pattern can be seen for Naming Vocabulary at both age 3 and 5 and Word Reading at age 7.

For Pattern Construction at age 5 and 7 and Number Skills at age 7 the dispersion of the score decreases until when children in families with an income below or equal to the ninth decile are in 
formal care, and the trend is reversed only when children from the richest families are in formal care. Also in these cases the percentage of children with low scores decreases constantly.

A completely different pattern emerges for Picture Similarity, which assesses the problem solving abilities of the child. With the growth of children in formal care, the coefficient of variation increases: this result arises because formal care by its own has a negative impact, which becomes positive when we take into account the interaction with the income decile. There is no effect on the percentage of children with low scores.

\author{
FIGURE 1 ABOUT HERE \\ FIGURE 2 ABOUT HERE \\ FIGURE 3 ABOUT HERE \\ FIGURE 4 ABOUT HERE \\ FIGURE 5 ABOUT HERE \\ FIGURE 6 ABOUT HERE \\ FIGURE 7 ABOUT HERE \\ FIGURE 8 ABOUT HERE
}

\title{
7. Conclusions
}

In this chapter, we investigate the impact of formal care for young children (18 months old) on their cognitive outcomes in the short term (age 3) and medium term (age 5 and 7). We allow the effect to be different depending on the level of education of the mother (measured by the age at which she left school). We find that on average children in formal care perform significantly better in School Readiness at age 3, Naming Vocabulary at age 5 and Number Skills at age 7; the effect is significantly larger for children with low educated mothers.

We simulate the effect of a policy which introduces formal care for all children from low socio-economic background (proxied by the income decile): attending the pre-kindergarten reduces the dispersion in terms of cognitive outcomes, until when children in families with an income below or equal to the sixth (ninth) decile are allowed to be in formal care. The percentage of children with low scores decreases steadily (with the only exception being Picture Similarity).

Therefore early childcare may have a role in reducing disparities as well as in decreasing the share of children with poor cognitive outcomes. In this direction, the entitlement to 15 hours of free early education to disadvantaged 2 year olds should be considered an effective policy. 


\section{References}

Bernal, R. (2008), 'The effect of maternal employment and child care on children's cognitive development’, International Economic Review, 49(4), 1173-1209.

Blanden, J., E. Del Bono, K. Hansen, S. McNally and B. Rabe (2014), 'Evaluating a demand-side approach to expanding free preschool education', Report presented as evidence to the House of Lords Select Committee on Affordable Childcare,http://www.nuffieldfoundation.org/sites/default/files/files/Childoutcomes_final.pdf

Brooks-Gunn, J., W. J. Han and J. Waldfogel (2002), 'Maternal employment and child cognitive outcomes in the first three years of life: The NICHD study of early child care', Child development, 73(4), 1052-1072.

Carneiro, Pedro and James J. Heckman (2003), 'Human capital policy’, in James J. Heckman, Alan B. Krueger and Benjamin M. Friedman (eds), Inequality in America: What Role for Human Capital Policies?, Cambridge, MA: MIT Press, pp. 77-239.

Datta Gupta, N. and M. Simonsen (2010), 'Noncognitive child outcomes and universal high quality child care', Journal of Public Economics, 94(1-2), 30-43.

Del Boca, D., C. Flinn and M. Wiswall (2014), 'Household Choices and Child Development', Review of Economic Studies, 81(1):137-185.

Felfe, C. and R. Lalive (2014), 'Early child care and child development: for whom it works and why', IZA Discussion Paper N. 7100, Institute for the Study of Labor.

Fitzpatrick, M. D. (2008), 'Starting school at four: the effect of universal pre-kindergarten on children's academic achievement', B.E. Journal of Economic Analysis and Policy, 8(1), 1-38.

Gibb, J., H. Jelicic and I. La Valle (2011), 'Rolling out free early education for disadvantaged two year olds: an implementation study for local authorities and providers', Research Report DFERR131, Department for Education.

Havnes, T. and M. Mogstad (2011), 'No child left behind. Universal childcare and children's longrun outcomes’, American Economic Journal: Economic Policy, 3, 97-129

Press, J. E., J. Fagan and L. Laughlin (2006), 'Taking Pressure Off Families: Child-Care Subsidies Lessen Mothers’ Work-Hour Problems', Journal of Marriage and the Family, 68(1), 155-171. 


\section{Tables}

Table 1. Average equivalent household income by mother's education

\begin{tabular}{lrr}
\hline Highest academic qualification & Obs. & HH income \\
\hline Higher degree & 367 & 582.9 \\
First degree & 1,470 & 525.2 \\
Diplomas in higher education & 932 & 405.4 \\
A/AS/S Levels & 984 & 371.3 \\
O level/ GCSE grades a-c & 3,166 & 302.2 \\
GCSE grades d-g & 906 & 229.8 \\
Other academic qualifications & 187 & 272.5 \\
None of these & 1,245 & 174.5 \\
\hline
\end{tabular}

Table 2. Children cognitive outcomes

\begin{tabular}{llllll}
\hline Variable & Observations & Mean & Std. dev. & Min & Max \\
\hline Age 3 & & & & & \\
School readiness & 9,088 & 105 & 16 & 56 & 149 \\
Naming vocabulary & 9,498 & 50 & 11 & 20 & 80 \\
Age 5 & & & & & \\
Naming vocabulary & 9,906 & 55 & 11 & 20 & 80 \\
Pattern construction & 9,874 & 51 & 10 & 20 & 80 \\
Picture similarity & 9,891 & 56 & 10 & 20 & 80 \\
Age 7 & & & & & \\
Pattern construction & 9,817 & 54 & 11 & 20 & 80 \\
Word reading & 9,729 & 112 & 18 & 55 & 145 \\
Number skills & 9,857 & 10 & 3 & 0 & 15 \\
\hline Maximum number of observations: $10,001$. & & & &
\end{tabular}

Table 3. Formal childcare and child cognitive skills (Age 3)

\begin{tabular}{lll}
\hline & School & Naming \\
& Readiness & Vocabulary \\
\hline Formal care & $7.72^{*}$ & 3.01 \\
& $(3.10)$ & $(2.09)$ \\
Mother's age when left school & $0.65^{* *}$ & $0.32^{* *}$ \\
& $(0.08)$ & $(0.05)$ \\
Formal*Mother's age when left school & $-0.36^{*}$ & $-0.22^{* *}$ \\
& $(0.16)$ & $(0.11)$ \\
\hline Observations & 9,088 & 9,498 \\
\hline${ }^{* *} \mathrm{p}<0.01,{ }^{*} \mathrm{p}<0.05,+\mathrm{p}<0.10$ & &
\end{tabular}


Table 4. Formal childcare and child cognitive skills (Age 5)

\begin{tabular}{llll}
\hline & Naming & Picture & Pattern \\
& Vocabulary & Similarity & Construction \\
\hline Formal care & $3.97^{*}$ & 1.79 & 3.04 \\
& $(2.01)$ & $(2.09)$ & $(2.00)$ \\
Mother's age when left school & $0.45^{* *}$ & $0.23^{* *}$ & $0.30^{* *}$ \\
& $(0.05)$ & $(0.05)$ & $(0.05)$ \\
Formal*Mother's age when left school & $-0.20+$ & -0.04 & -0.15 \\
& $(0.11)$ & $(0.11)$ & $(0.10)$ \\
\hline Observations & 9,906 & 9,891 & 9,874 \\
${ }^{* *} \mathrm{p}<0.01{ }^{*} \mathrm{p}<0.05,+\mathrm{p}<0.10$ & & &
\end{tabular}

Table 5. Formal childcare and child cognitive skills (Age 7)

\begin{tabular}{llll}
\hline & Pattern & Word & Number \\
& Construction & Reading & Skills \\
\hline Formal care & 2.48 & 2.03 & $1.43^{* *}$ \\
& $(2.20)$ & $(3.48)$ & $(0.54)$ \\
Mother's age when left school & $0.37^{* *}$ & $0.71^{* *}$ & $0.10^{* *}$ \\
& $(0.05)$ & $(0.08)$ & $(0.01)$ \\
Formal*Mother's age when left school & -0.12 & -0.12 & $-0.07^{*}$ \\
& $(0.12)$ & $(0.18)$ & $(0.03)$ \\
\hline Observations & 9,817 & 9,729 & 9,857 \\
\hline$* * \mathrm{p}<0.01^{*} \mathrm{p}<0.05, \mathrm{p}<0.10$ & & &
\end{tabular}




\section{FIGURES}

FIGURE 1: School Readiness (age 3)

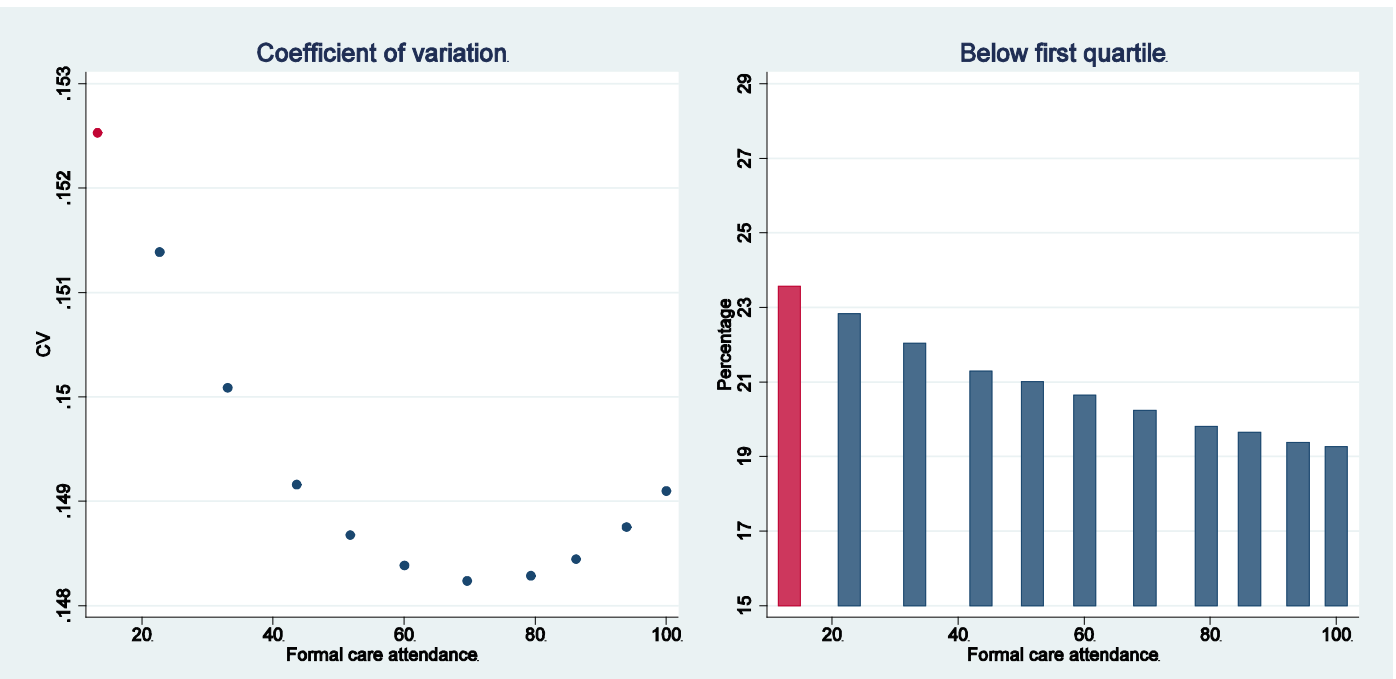

FIGURE 2: Naming Vocabulary (age 3)
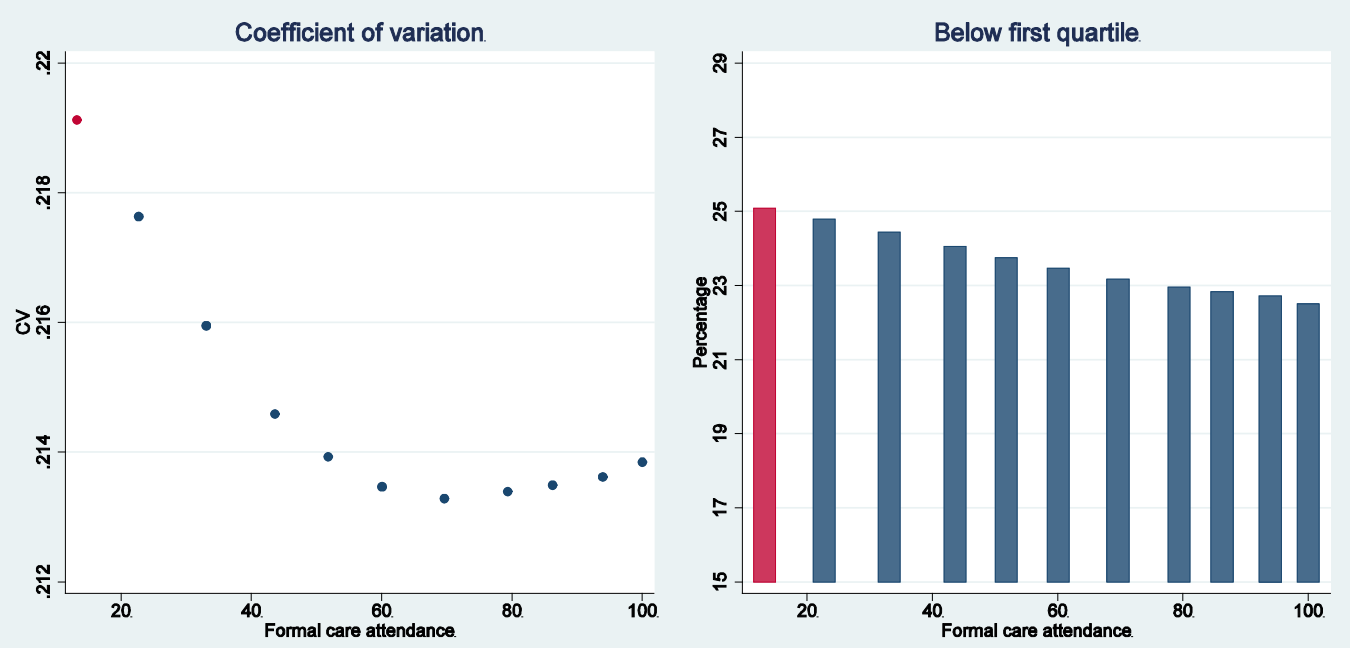
FIGURE 3: Naming Vocabulary (age 5)

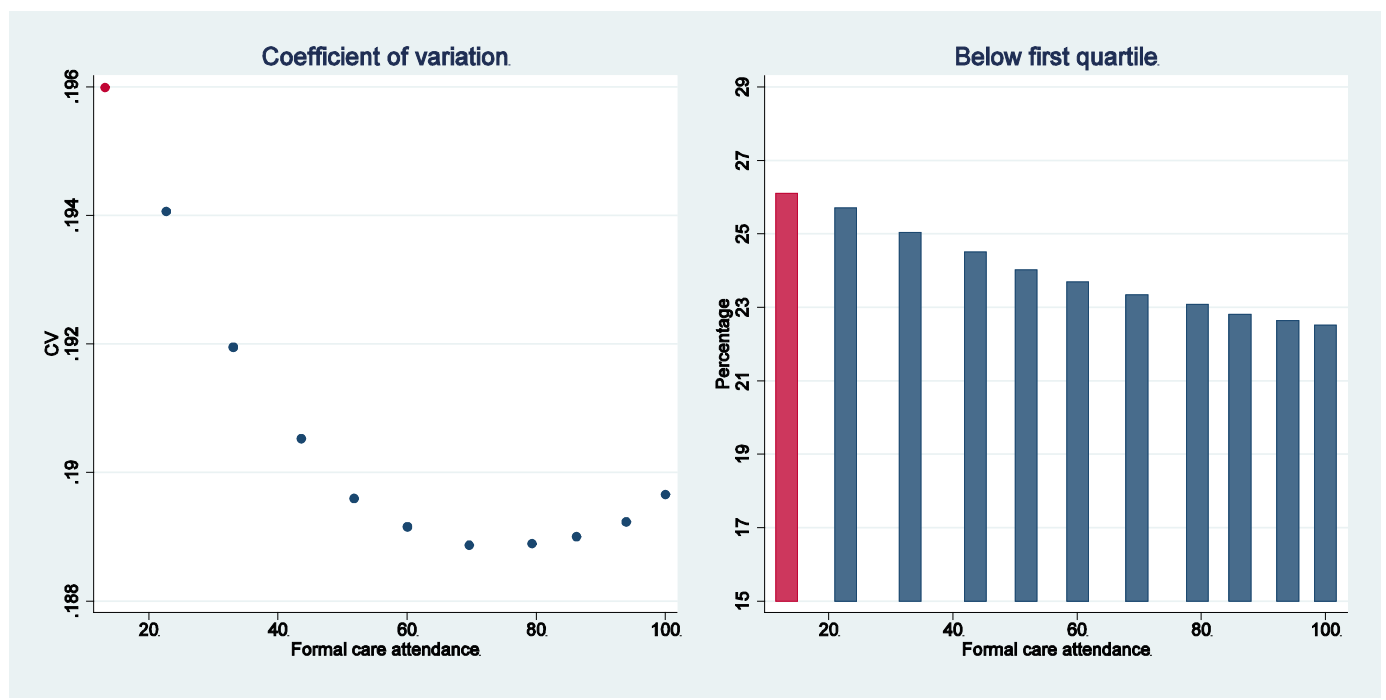

FIGURE 4: Picture Similarity (age 5)

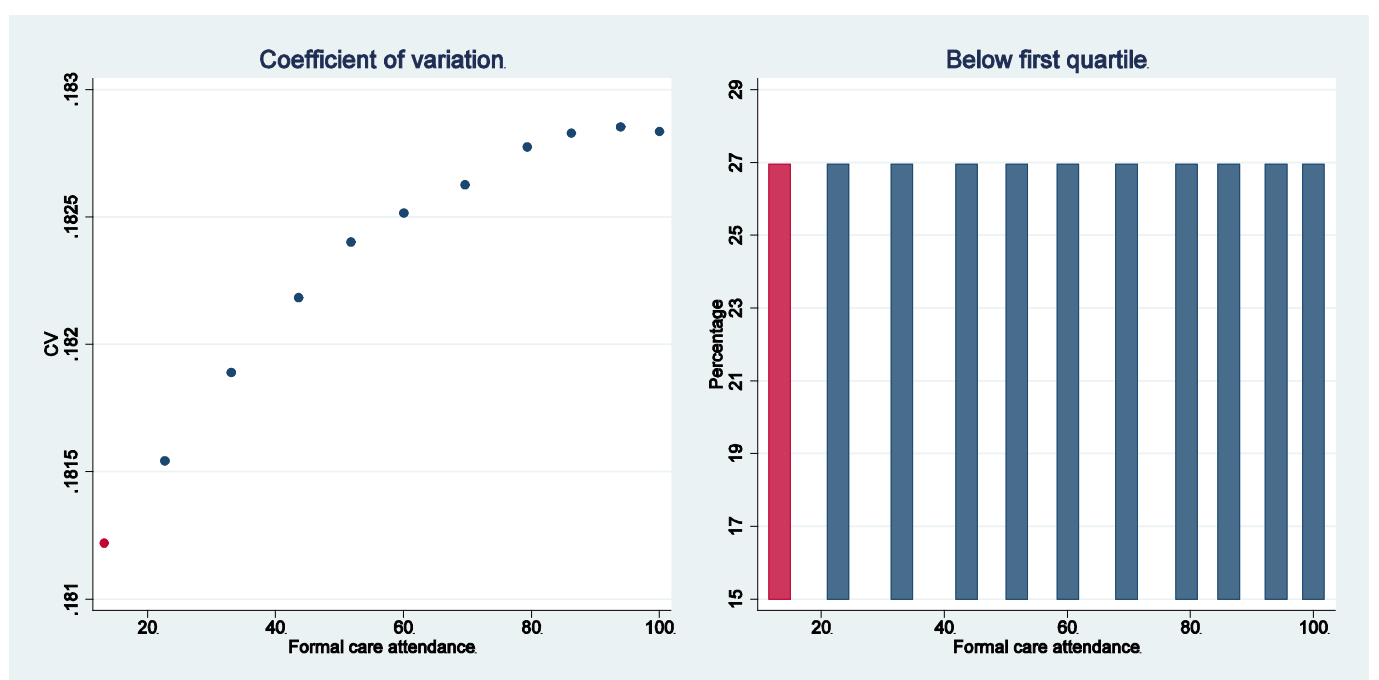

FIGURE 5: Pattern Construction (age 5) 


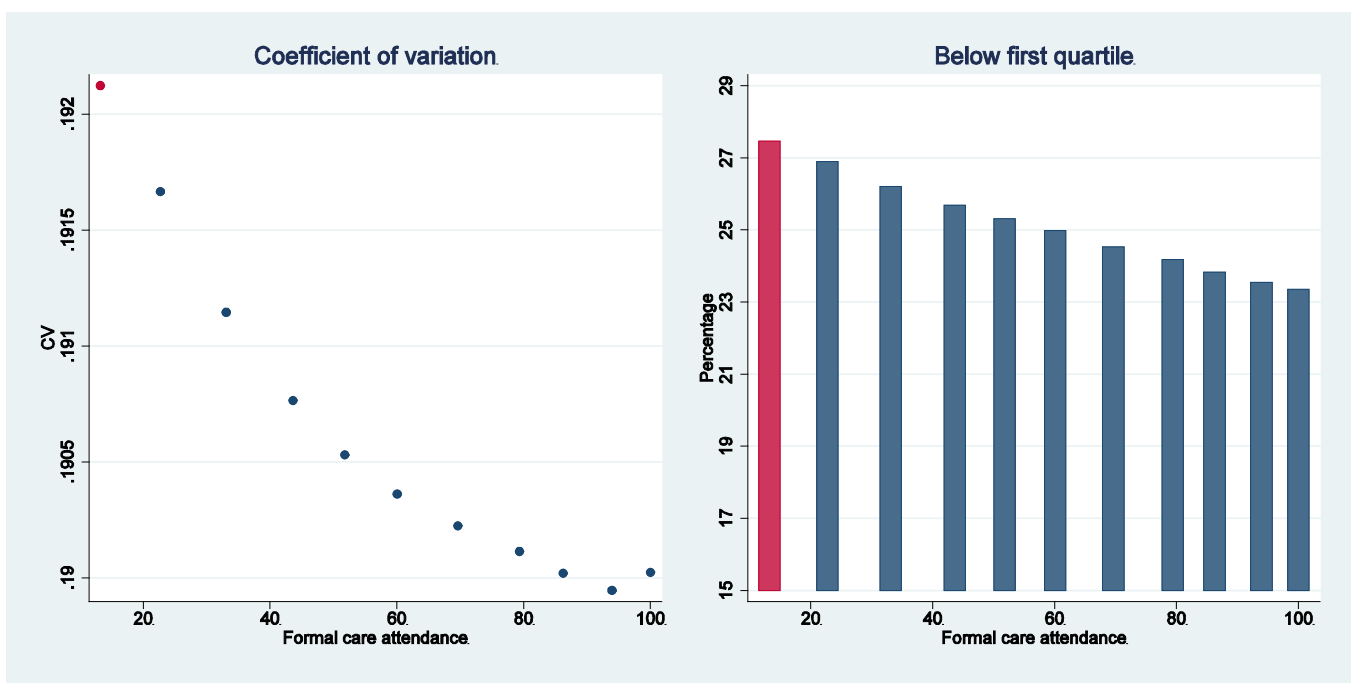

FIGURE 6: Pattern Construction (age 7)
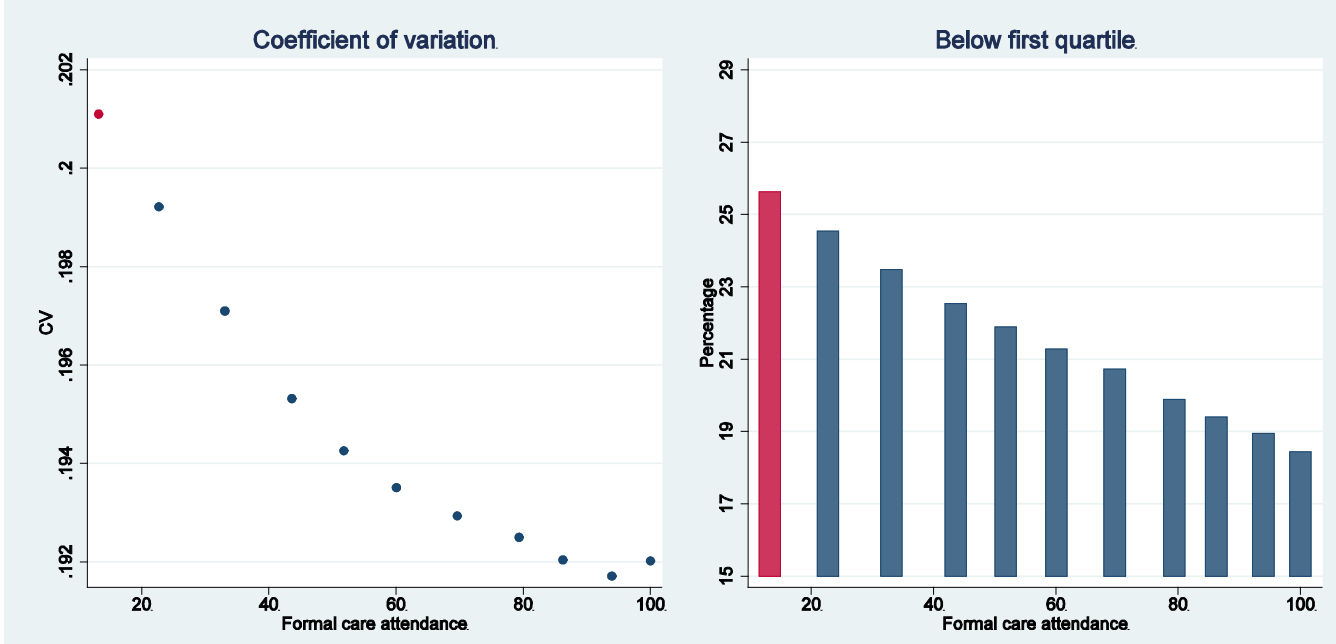

FIGURE 7: Word Reading (age 7)
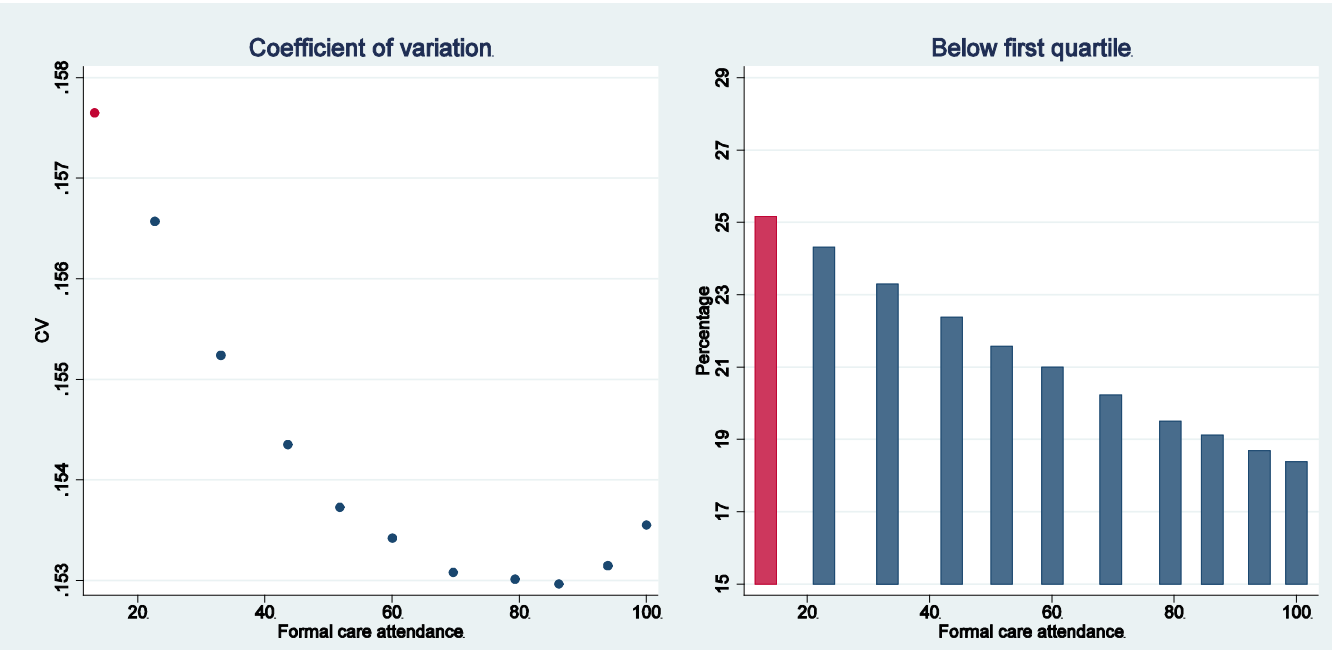
FIGURE 8: Number Skills (age 7)

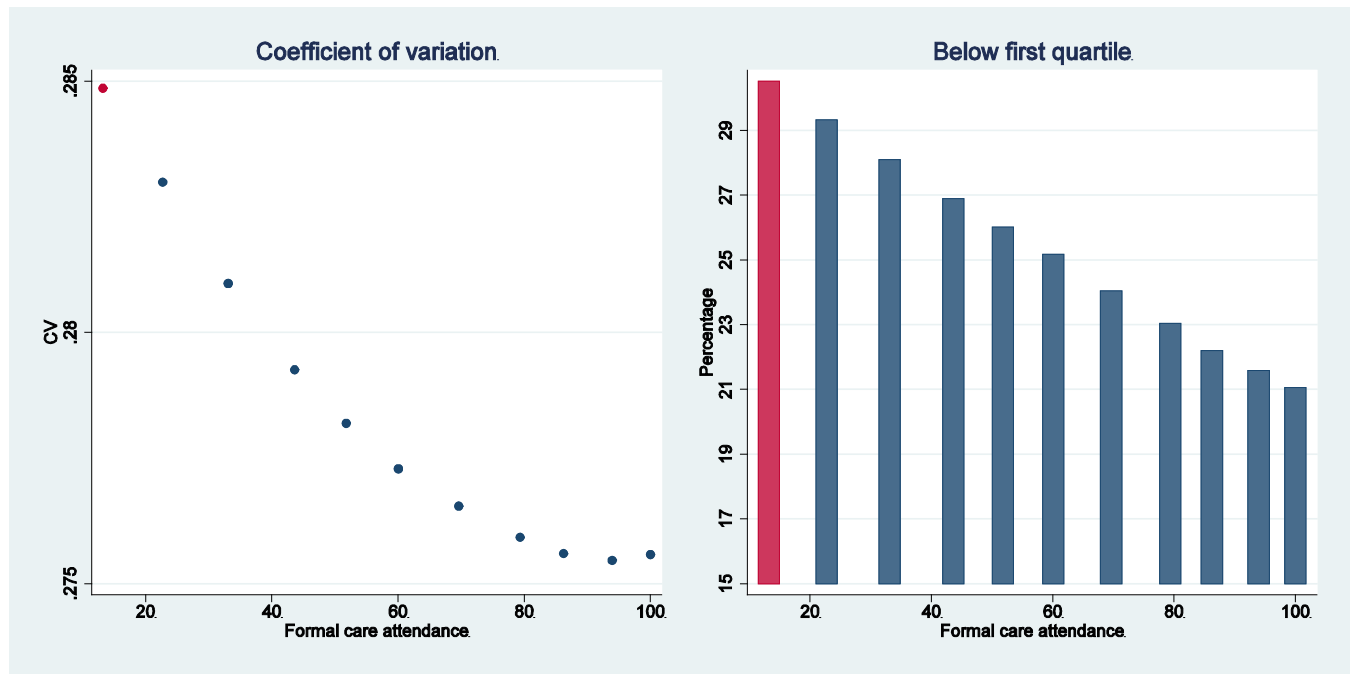

